\title{
Long-term biventricular support with rotary blood pumps in a patient with a noncontractile heart
}

\author{
Taichi Sakaguchi, MD, Shunsuke Saito, MD, Daisuke Yoshioka, MD, and Yoshiki Sawa, MD, Osaka, Japan
}

Despite advances in continuous-flow ventricular assist devices (VADs), their long-term use for biventricular support is still limited. We report a case of successful longterm biventricular support using 2 rotary pumps implanted in a patient completely lacking native cardiac contractility.

\section{CASE REPORT}

A 34-year-old woman (body surface area, $1.56 \mathrm{~m}^{2}$ ) underwent emergency biventricular VAD implantation with paracorporeal pulsatile devices (Nipro Medical Corp, Miami, Fla) for fulminant myocarditis. After 6 months, biventricular VAD conversion to implantable continuousflow pumps was performed for long-term support. The intraoperative findings showed that both ventricles were not dilated and were totally noncontractile, serving only as inert blood conduits. A DuraHeart (Terumo Heart Inc, Ann Arbor, Mich) was chosen as the left VAD because the inflow cannulas of both devices are virtually the same size and the previous Nipro inflow cuff was usable. A Jarvik 2000 (Jarvik Heart Inc, New York, NY) was placed on the right ventricle. The anterior leaflet of the tricuspid valve was sutured to the anterior wall of the right ventricle to prevent inflow obstruction and to create a single atrioventricular pouch for systemic venous return. Because the patient had severe pulmonary insufficiency, the pulmonary valve was closed with a running suture. Each outflow graft was anastomosed to the previous outflow graft, and no banding was added to the right VAD outflow graft (Figure 1).

Her postoperative course was uneventful, and she successfully underwent heart transplantation after 884 days of biventricular support.

\section{DISCUSSION}

Several reports have been published of implantable continuous-flow pumps being used for long-term biventricular support. The largest study was reported by the Berlin

\footnotetext{
From the Department of Cardiovascular Surgery, Osaka University Graduate School of Medicine, Osaka, Japan.

This study was supported by Health and Labour Sciences Research grants from the Ministry of Health, Labour and Welfare of Japan.

Disclosures: Authors have nothing to disclose with regard to commercial support.

Received for publication June 6, 2013; accepted for publication June 18, 2013; available ahead of print July 22, 2013.

Address for reprints: Taichi Sakaguchi, MD, Department of Cardiovascular Surgery, Osaka University Graduate School of Medicine, 2-2 Yamadaoka, Suita, Osaka 565-0871, Japan (E-mail: ts472@tuba.ocn.ne.jp).

J Thorac Cardiovasc Surg 2013;146:e29-30

$0022-5223 / \$ 36.00$

Copyright (c) 2013 by The American Association for Thoracic Surgery

http://dx.doi.org/10.1016/j.jtcvs.2013.06.015
}

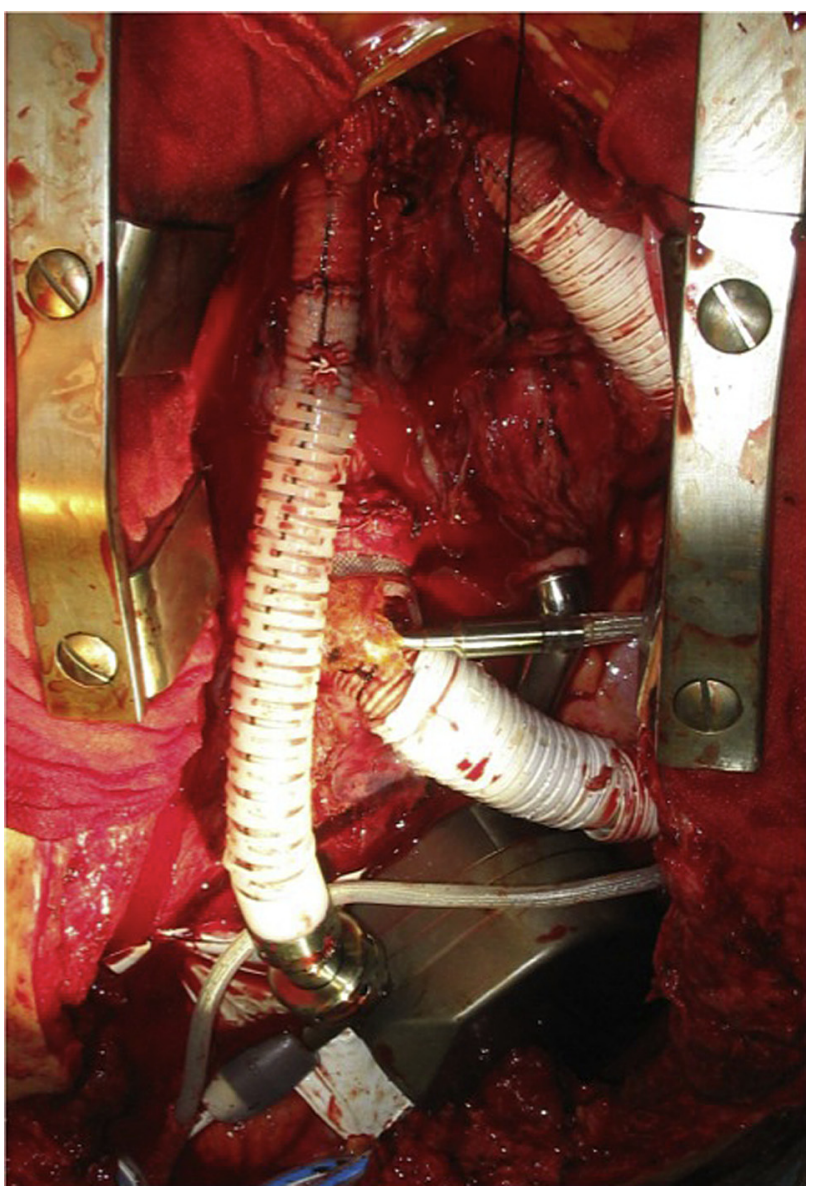

FIGURE 1. Intraoperative view showing implanted Jarvik 2000 right ventricular assist device and DuraHeart left ventricular assist device. Reprinted with permission. ${ }^{3}$

Heart Institute Group, in which 17 patients were implanted with 2 HeartWare HVAD pumps (Heartware International Inc, Framingham, Mass). In those patients, the 30-day survival was $82 \%$, with the longest survival period reaching 440 days. The preoperative left and right ventricular ejection fraction value was $20.2 \% \pm 12.4 \%$ and $29.9 \%$ $\pm 11.7 \%$, respectively.

The present patient had lost all ventricular contractility owing to massive myocardial necrosis (Figure 2) and had been in nonpulsatile circulation for $>2$ years. Patients supported with continuous-flow VADs commonly still have some degree of pulsatile blood pressure caused by native ventricular contraction. In this context, little is known regarding the long-term influence of nonpulsatile circulation on the human body. In our patient, no significant changes were observed in the laboratory values showing end-organ 


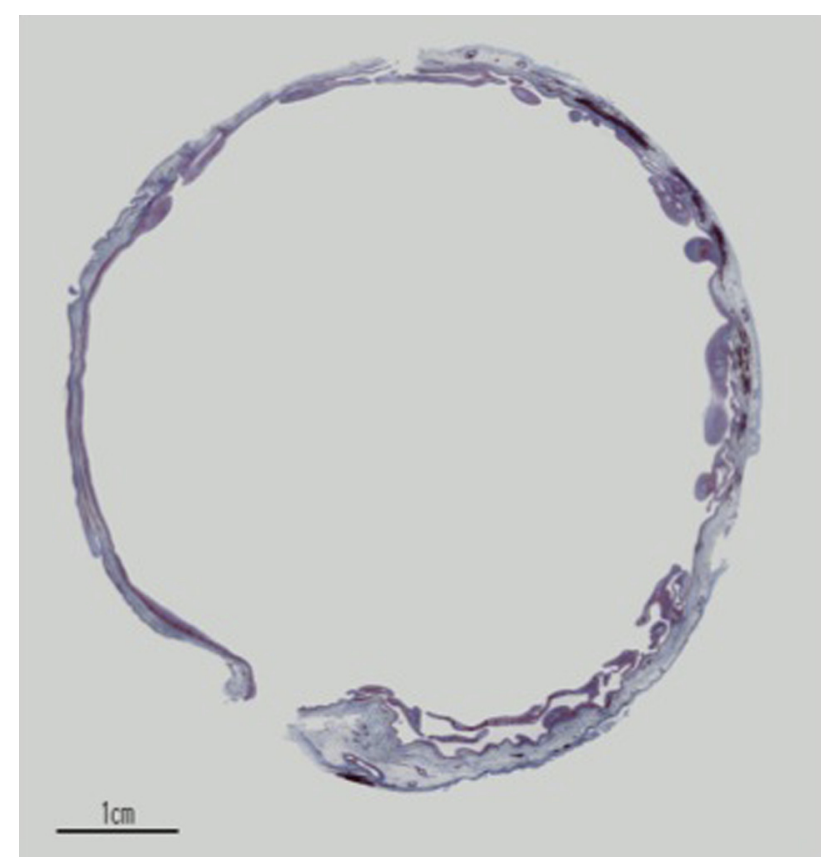

FIGURE 2. Histologic findings of the explanted heart showing an extremely thin left ventricular wall with marked fibrosis (elastica van Gieson's stain).

function. Furthermore, an exercise stress test showed increased left VAD flow even at a fixed pump speed. Frazier et $\mathrm{al}^{2}$ used a calf model in which both native ventricles were excised and replaced with 2 continuous-flow VADs. An exercise test demonstrated increased flow in both VADs. ${ }^{2}$ Our results have confirmed their experimental findings, suggesting that even without native ventricular contraction, biventricular VADs can adjust their flow according to the flow demand. We consider that these hemodynamic properties imply the possibility of clinical use of continuous-flow artificial hearts currently being tested in animal models.

When implanting 2 rotary pumps for biventricular support, concern exists about a flow imbalance between the pulmonary and systemic circulation. After the implant operation, the systemic and pulmonary vascular resistances become dynamic and are further influenced by use of inotropes, discontinuation of mechanical ventilation, and other factors. These altered hemodynamic states could exacerbate the flow imbalance during the perioperative period, especially in patients with a noncontractile heart. In the present case, the first extubation failed owing to severe pulmonary congestion caused by right VAD overflow. ${ }^{3}$ Interestingly, after resolution of these perioperative hemodynamic fluxes, the management became easier, with no additional pulmonary congestion noted. A natural flow balance appears to be achieved by the autoregulatory properties of continuous-flow VADs. ${ }^{4}$

The currently available pulsatile total artificial hearts have numerous restrictions. We believe that the present successful case will promote the clinical use of rotary blood pumps in patients with biventricular failure for bridging and, even, destination therapy.

\section{References}

1. Krabatsch T, Potapov E, Stepanenko A, Schweiger M, Kukucka M, Huebler M, et al. Biventricular circulatory support with two miniaturized implantable assist devices. Circulation. 2011;124:S179-86.

2. Frazier OH, Cohn WE, Tuzon E, Winkler JA, Gregoric ID. Continuous flow total artificial heart supports long-term survival of a calf. Tex heart Inst J. 2009;36:568-74.

3. Saito S, Sakaguchi T, Miyagawa S, Yoshikawa Y, Yamauchi T, Ueno T, et al. Biventricular support using implantable continuous-flow ventricular assist devices. J Heart Lung Transplant. 2011;30:475-8.

4. Westaby S, Frazier OH. Long-term biventricular support with rotary blood pumps: prospects and pitfalls. Eur J Cardiothorac Surg. 2012;42:203-8.

\title{
Acquired von Willebrand disease in a child with a ventricular assist device
}

\author{
Karine Nubret, MD, ${ }^{\mathrm{a}}$ Philippe Mauriat, MD, ${ }^{\mathrm{a}}$ François Roubertie, MD, ${ }^{\mathrm{b}}$ Chloé James, MD, $, \mathrm{d}, \mathrm{e}$ \\ Nadir Tafer, MD, ${ }^{\mathrm{a}}$ and Alexandre Ouattara, $\mathrm{MD}, \mathrm{PhD},{ }^{\mathrm{a}, \mathrm{d}, \mathrm{e}}$ Bordeaux and Pessac, France
}

\footnotetext{
From Service d'Anesthésie-Réanimation II, ${ }^{\mathrm{a}}$ Service de Chirurgie Cardiovasculaire, ${ }^{\mathrm{b}}$ and Laboratoire d'Hématologie-Hémostase, ${ }^{\mathrm{c}} \mathrm{CHU}$ de Bordeaux, Bordeaux, France; and Adaptation Cardiovasculaire à l'Ischémie, ${ }^{\mathrm{d}}$ University of Bordeaux, and Adaptation Cardiovasculaire à l'Ischémie, ${ }^{\mathrm{e}}$ INSERM, Pessac, France.

Disclosures: Authors have nothing to disclose with regard to commercial support.

Received for publication Feb 3, 2013; revisions received April 21, 2013; accepted for publication June 18, 2013; available ahead of print July 26, 2013.

Address for reprints: Alexandre Ouattara, MD, PhD, Service d'AnesthésieRéanimation 2, Hôpital Haut-Lévèque-CHU de Bordeaux, Avenue de Magellan, F-33604 Pessac, France (E-mail: alexandre.ouattara@chu-bordeaux.fr).

J Thorac Cardiovasc Surg 2013;146:e30-2

0022-5223/\$36.00

Copyright (C) 2013 by The American Association for Thoracic Surgery

http://dx.doi.org/10.1016/j.jtcvs.2013.06.023
}

The ventricular assist device (VAD), as a bridge to heart transplantation, is being increasingly used in patients of all ages who are experiencing refractory heart failure. In these patients, massive bleeding remains a leading and challenging complication. Among the possible causes, the occurrence of acquired von Willebrand disease (avWD) has been reported in adult patients. ${ }^{1}$ Indeed, the loss of high-molecular-weight (HMW) von Willebrand factor (vWF) multimers because of shear stress, similar to that seen in aortic stenoses, ${ }^{1}$ is frequently observed in patients with axial flow in a left VAD. ${ }^{2,3}$ 